\section{ABSOLUTE CONFIGURATION OF EPIDERSTATIN, A NEW GLUTARIMIDE ANTIBIOTIC PRODUCED BY \\ Streptomyces pulveraceus}

\section{TADAMICHI SONODA, Kimiko Kobayashi, \\ Makoto Ubukata, ${ }^{*}$ Hiroyuki Osada and $\mathrm{KIYOSHI} \mathrm{ISONO}^{\dagger}$}

The Institute of Physical and Chemical Research (RIKEN), Wako-shi, Saitama 351-01, Japan

(Received for publication July 29, 1992)

Epiderstatin was isolated as a potent inhibitor of the signal transduction induced by EGF in quiescent $\mathrm{Balb} / \mathrm{MK}$ cells ${ }^{1)}$. The chemical structure of the compound was proposed as 4-[3-((Z)-3,5dimethyl-2-oxopiperidine-6-ylidene)-2-oxopropyl]2,6-piperidinedione on the basis of spectroscopic evidence ${ }^{2)}$. On comparison with other glutarimide antibiotics, epiderstatin is unique in containing a vinylogous amide. However, the relative configuration at $\mathrm{C}-3$ and $\mathrm{C}-5$ in its structure could not be determined by the ${ }^{1} \mathrm{H}$ NMR spectral analysis because the methine proton signals of $3-\mathrm{H}, 5-\mathrm{H}$ and $10-\mathrm{H}$ overlapped.

We report herein the relative configuration of epiderstatin and also its absolute configuration (Fig. 1) which were determined by means of X-ray analysis, and COSMIC force-field energy calculation and circular dichroism (CD) analysis, respectively.

\section{Results and Discussion}

The molecular structure of epiderstatin determined by X-ray crystallography (Fig. 2) showed that the relative configurations at $\mathrm{C}-3$ and $\mathrm{C}-5$ could be either $S / S$ or $R / R$.

To determine the absolute configuration of epiderstatin, COSMIC force-field calculation and $\mathrm{CD}$ analysis were carried out. On the basis of the $\mathrm{X}$-ray data, the steric energies of the two hypothetical conformations of epiderstatin in COSMIC force-field were calculated with the analytical program Nemesis (Fig. 3) ${ }^{3}$. The steric energy of the $5-\mathrm{CH}_{3}$ axial conformer $(18.0 \mathrm{kcal} / \mathrm{mole})$ is thermodynamically lower than that of the $3-\mathrm{CH}_{3}$ axial conformer $(22.3 \mathrm{kcal} / \mathrm{mole})$, therefore, the $5-\mathrm{CH}_{3}$ axial conformer, which has a pseudoaxial methyl at the $\mathrm{C}-5$ position, is more stable than the $3-\mathrm{CH}_{3}$ axial conformer. The stability of the $5-\mathrm{CH}_{3}$ axial conformer could be justified by the van der Waals repulsion between $5-\mathrm{CH}_{3}$ and $7-\mathrm{H}$. This conformation in solution was also confirmed from the NOE experiments which show that the $5-\mathrm{CH}_{3}$ exists predominantly in a pseudoaxial position, because the NOE between $5-\mathrm{H}$ and $7-\mathrm{H}(5.5 \%)$ is larger than that between $5-\mathrm{CH}_{3}$ and $7-\mathrm{H}(0.7 \%)^{2)}$. Thus, the $5-\mathrm{CH}_{3}$ axial conformation in solution was deduced from both COSMIC force-field calculation and $\mathrm{X}$-ray crystallography in combination with NOE experiments.

The circular dichroism (CD) curve (Fig. 4) of the compound in $\mathrm{CH}_{3} \mathrm{OH}$ showed a positive Cotton effect $(\Delta \varepsilon+0.165)$ at $285 \mathrm{~nm}$. An application of the allylic axial chirality approach ${ }^{4)}$ for the longwavelength $\pi-\pi^{*}$ transition Cotton effect of the cisoid conjugated enone system indicated that the absolute configuration of C-5 is $S$. The shift of the $K$ band to longer wavelength is probably due to the existence of the electron-donating amide-nitrogen, $\mathrm{N}-1$, on which the unshared electron pair interacts

Fig. 1. Absolute configuration of epiderstatin.

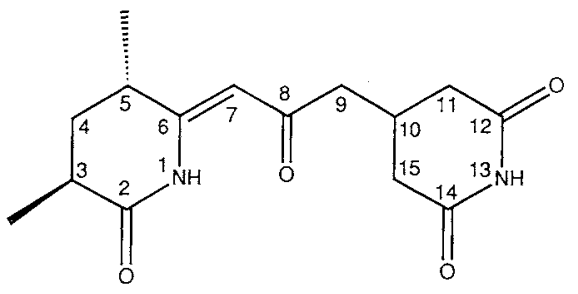

Fig. 2. Molecular structure of epiderstatin.

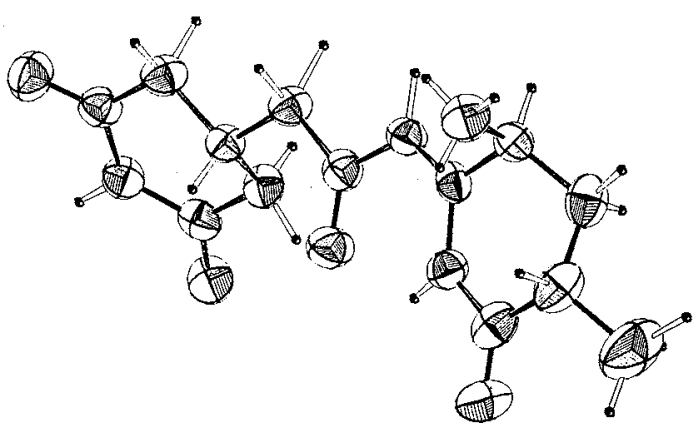

$\dagger$ Present address: Department of Marine Science, School of Marine Science and Technology, Tokai University, 3-20-1, Orido, Shimiza, Shizuoka 424, Japan. 
Fig. 3. Steric conformation of epiderstatin estimated by the COSMIC force-field method.

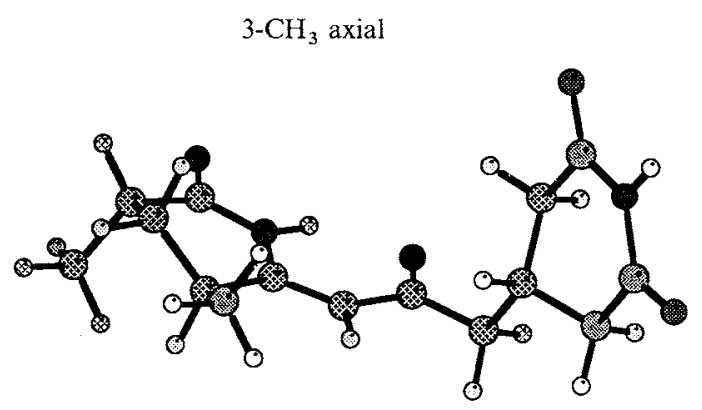

Total energy: $22.3 \mathrm{kcal} / \mathrm{mole}$

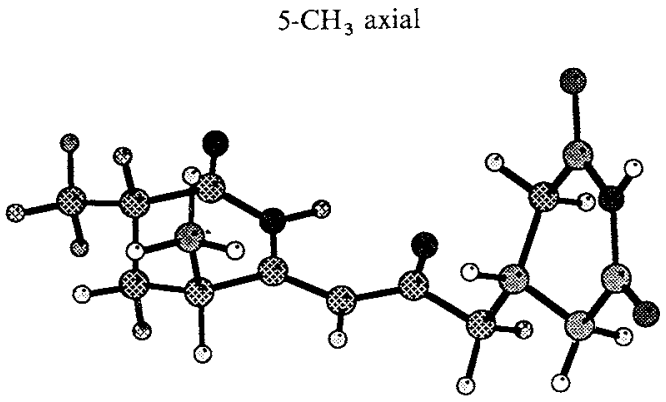

Total energy: $18.0 \mathrm{kcal} / \mathrm{mole}$

with the delocalised $\pi$ orbitals of the conjugated enone. It was thus concluded that the absolute configuration of epiderstatin is $(3 S, 5 S)$ as shown in Fig. 1. This configuration corresponds to that of cycloheximide $^{5)}$, which suggests that the both compounds are derived from a common biosynthetic precursor.

Two independent synthesis of ( \pm )-epiderstatin were recently reported ${ }^{6.7)}$, and the Pfizer group ${ }^{6)}$ indicated the $\mathrm{C}-3 / \mathrm{C}-5$ relative stereochemistry as trans.

\section{Experimental}

Epiderstatin was isolated from the culture fluid of Streptomyces pulveraceus subsp. epiderstagenes as described in ref 1 . Crystals were obtained from methanol-water $(1: 1)$ in a refrigerator.

\section{Crystal Data}

$\frac{\mathrm{C}_{15} \mathrm{H}_{20} \mathrm{~N}_{2} \mathrm{O}_{4}}{4}, M w=292.33$, orthorhombic, $a=$ $10.938(2), b=23.871(6), c=5.851(1) \AA, V=1527.7(6)$
Fig. 4. CD curve of epiderstatin.

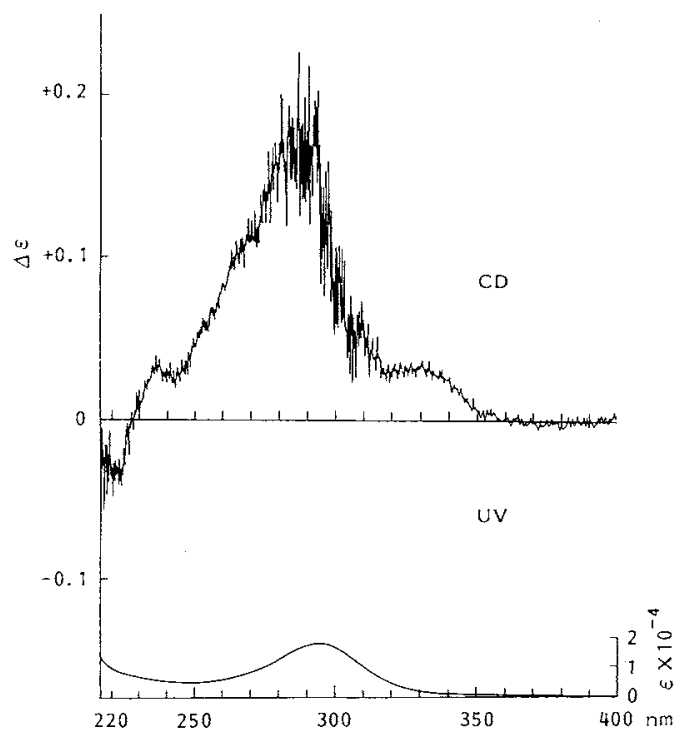

$\AA^{3}$, space group $P 22_{1} 2_{1}{ }_{1}, Z=4, D x=1.271 \mathrm{~g} / \mathrm{cm}^{3}$, $\mu(\mathrm{Mo}-\mathrm{K} \alpha)=0.87 \mathrm{~cm}^{-1}, F(000)=624$. Lattice parameters were determined from 20 reflections with $20^{\circ}<2 \theta<23^{\circ}$.

\section{Data Collection and Processing}

A transparent colorless prism crystal $(0.14 \times$ $0.22 \times 0.80 \mathrm{~mm}$ ) was mounted on a Rigaku AFC-4 diffractometer. Intensity data were measured using graphite-monochromated $\mathrm{Mo}-\mathrm{K} \alpha$ radiation, $\lambda=$ $0.7073 \AA$, in the $\omega$-scan mode $\left(0\right.$ to $\left.30^{\circ}\right)$ and $\omega-2 \theta$ scan mode $\left(30^{\circ}<2 \theta\right)$. The three standard reflections showed no significant deterioration. The intensities were corrected for $L p$ factors. Within the range of $2 \theta \leqq 55^{\circ}, 1,307$ reflections were measured and 1,239 unique reflections obtained with $\left|F_{\mathrm{O}}\right|>3 \sigma\left(\left|F_{\mathrm{O}}\right|\right)$.

\section{Structure Analysis and Refinement}

The structure of epiderstatin was solved by the direct methods using the program MULTAN78 ${ }^{8}$ ) and refined by the block-diagonal least-squares. All $\mathrm{H}$ atom positions were located from a difference Fourier synthesis. All non-hydrogen atoms were refined anisotropically and $\mathrm{H}$ atoms isotropically. Both final $R$ and $R w$ values were 0.046 . Crystallographic calculations were performed on a FACOM M-780 computer using UNICS-III program system ${ }^{9}$. The source of scattering factor data was given by International Tables for X-ray Crystallography $(1974)^{10)}$. 
Calculation of Steric Energy of Epiderstatin

The steric conformations of epiderstatin were built up by three dimensional graphics on a Macintosh computer. On the basis of these structure, each steric energy was calculated by the COSMIC force-field method using a Nemesis program (Oxford Molecular Ltd.) $)^{3)}$.

\section{Determination of Circular Dichroism (CD)}

The CD spectrum of epiderstatin was determined with a JASCO J-20 Automatic Recording Spectropolarimeter at a concentration of $50 \mu \mathrm{g} / \mathrm{ml}$ in methanol. The scanning conditions were as follows: scanning speed, $4 \mathrm{~mm} /$ minute; temperature, $25^{\circ} \mathrm{C}$; cell length, $10 \mathrm{~mm}$; scale, $1.0 \mathrm{~mm}^{\circ} / \mathrm{cm}$.

\section{References}

1) Osada, H.; T. Sonoda, H. Kusakabe \& K. Isono: Epiderstatin, a new inhibitor of the mitogenic activity induced by epidermal growth factor. I. Taxonomy, fermentation, isolation and characterization. J. Antibiotics 42: $1599 \sim 1606,1989$

2) Sonoda, T.; H. Osada, M. Uramoto, J. Uzawa \& $\mathrm{K}$. Isono: Epiderstatin, a new inhibitor of the mitogenic activity induced by epidermal growth factor. II. Structure elucidation. J. Antibiotics 42: $1607 \sim 1609,1989$
3) Vinter, J. G.; A. Davis \& M. R. Saunders: J. Compt.-Aided Mol. Design 1: 31, 1987

4) Burgstahler, A. W. \& R. C. Barkhurst: $\pi-\pi^{*}$ region Cotton effects of cyclic conjugated dienes and enones. Interpretation in terms of allylic axial chirality contributions. J. Am. Chem. Soc. 92: $7601 \sim 7603,1970$

5) VaneK, Z.; M. Puza, J. Cudlin \& L. Dolezilova: Metabolites of Streptomyces noursei. III Incorporation of ${ }^{14} \mathrm{C}$-carbon dioxide into cycloheximide. Biochem. Biophys. Res. Commun. 17: 532 535, 1964

6) Dow, R. L.; M. A. Hain \& J. A. Lowe III: Total synthesis and stereochemical assignment of $( \pm)$ epiderstatin. Tetrahedron Lett. 33: 309 312, 1992

7) Ubukata, M.; T. Sonoda \& K. Isono: Synthesis of ( \pm -epiderstatin. Natural Product Lett. 1: 149 154, 1992

8) Main, P.; S. E. Hull, L. Lessinger, G. Germain, J.-P. DeClerce \& M. M. Woolfson: MULTAN78, A Program for the Automatic Solution of Crystal Structures from X-Ray Diffraction Data. Univs. of York, England, and Louvain, Belgium, 1978

9) SAKuraI, T. \& K. KOBAYASHI: On the universal crystallographic computation program system (5). UNICS III system. Rep. Inst. Phys. Chem. Res. 55: $69 \sim 77,1979$

10) International Tables for X-Ray Crystallography. Vol IV. Birmingham, Kynoch Press, 1974 